\title{
EL RÉGIMEN CONSTITUCIONAL DE LOS DERECHOS EN BOLIVIA: DE LA CONSTITUCIÓN A LA JURISPRUDENCIA. UN BREVE REPASO SOBRE SU APLICACIÓN
}

\author{
THE CONSTITUTIONAL LAW OF RIGHTS IN BOLIVIA: FROM THE \\ CONSTITUTION TO THE JURISPRUDENCE. A SHORT REVIEW ABOUT \\ ITS APPLICATION
}

\author{
Horacio Andaluz Vegacenteno \\ Universidad Privada de Santa Cruz de la Sierra. Bolivia/Bolivia \\ handaluz@post.harvard.edu
}

Recibido/Received: 11/08/2014

Aceptado/Accepted: 23/09/2014

\section{RESUMEN}

Este es un artículo sobre el desarrollo jurisprudencial de los derechos proclamados en la Constitución boliviana. El artículo se ha limitado a estudiar los aspectos que la jurisprudencia ha considerado formales y, en consecuencia, comunes a todos los derechos de índole constitucional en el ordenamiento boliviano. A cinco años de la entrada vigor de la Constitución de 2009, el Tribunal Constitucional ha desarrollado un vasto cuerpo de jurisprudencia sobre los proclamados por ella. Sin ser un análisis exhaustivo, el artículo pretende sólo hacer un breve repaso de ese desarrollo.

\section{PALABRAS CLAVE}

Derechos fundamentales, constitución, jurisprudencia, interpretación constitucional, precedentes, eficacia directa, acciones constitucionales.

\section{SUMARIO}

1. Eficacia directa. 2. Interpretación según los tratados de derechos humanos. 3. Reserva material de Ley. 4. Tutela en sede constitucional.

\begin{abstract}
This article is about the jurisprudential developments of the rights written in the Bolivian Constitution. The article is limited to the formal aspects developed by the decisions of the Constitutional Court. Therefore, they are equally applicable to all the constitutional rights in the Bolivian legal system. After five years of application of the Constitution of 2009, the Constitutional Court has developed a wide body of jurisprudence about the fundamental rights it proclaims. This article only pretends to do a short review of such developments.
\end{abstract}

\section{KEYWORDS}

Fundamental rights, Constitution, jurisprudence, constitutional interpretation, precedent, direct Efficacy, constitutional actions.

\section{CONTENTS}

1. Direct Efficacy. 2. Interpretation according with human rights treaties. 3. Prerogative of the Legislature to regulate fundamental rights. 4 . Protection by the Constitutional Court. 


\section{EFICACIA DIRECTA}

Fundar la eficacia directa de los derechos en el artículo 109.I de la Constitución, y asumir que ello es una innovación del texto de 2009, significa (1) negar el carácter normativo de la propia Constitución y (2) confesar desconocimiento de la historia constitucional.

(1) Significa lo primero, porque equivale a sostener que una norma constitucional sólo rige como tal si la propia norma así lo establece. A contrario, implica afirmar que si la propia Constitución no predica de alguna de sus normas su carácter obligatorio, carece de tal virtud. Absurdo. Los derechos establecidos por cualquiera de sus normas son directamente aplicables por el solo hecho de estar inscritos en la Constitución; y para el caso boliviano esto viene desde 1826 (artículos 149 a 157). Es una consecuencia del carácter normativo de la Constitución. Si ella existe con la dignidad de una auténtica norma jurídica, entonces su contenido, por el solo hecho de estar regulado en su texto, es, en efecto, jurídicamente exigible. Artículos como el 109.I son, por consiguiente, una redundancia del carácter normativo que ostenta la Constitución como norma jurídica (acaso importante como reduplicación enfática de lo obvio en un contexto social que no exhibe precisamente la mejor tradición de respeto a las normas, pero que, al margen tal finalidad enteramente pedagógica, carece de toda relevancia propiamente normativa).

(2) Y, confiesa lo segundo, porque ignora que al decir "[los derechos] no necesitan de reglamentación previa para su cumplimiento", la Constitución, desde sus reformas de 1945 (artículo 28), ya contenía una norma redundante de su carácter normativo, y que, con distinta ubicación en el articulado, estuvo vigente con ese mismo texto por más de sesenta años, dando forma al anterior artículo 229. Gramaticalmente estaba formulada en sentido negativo, mientras que hoy ha tomado la forma de una afirmación ("[los derechos] son directamente aplicables"). No sería correcto mezquinarle al cambio una vocación pedagógica, pero tampoco lo sería atribuirle un carácter de innovación normativa.

Que los derechos sean directamente aplicables significa (1) que puede reivindicarse su tutela en cualquier actuación procesal con el solo fundamento de la norma constitucional, (2) que su falta de desarrollo legislativo no es obstáculo para su aplicación y (3) que debe interpretárselos a favor de su ejercicio. En lo formal, las tres son consecuencias del carácter normativo de la Constitución; en lo material, lo son de la filosofía política liberal que la inspira.

(1) Respecto a la primera, si el cometido de la Constitución es instituir un gobierno de poderes limitados sometiéndolos a sus mandatos, entonces su sola invocación ya compromete a los poderes públicos a dar al peticionante una respuesta fundada en derecho. Y si ocurre que los derechos constitucionales invocados han sido objeto de desarrollo legislativo, y el peticionante no ha cumplido las condiciones impuestas por la ley para su tutela, será tal acto propio el fundamento para denegar la tutela solicitada, pero no la sola falta de invocación de dichas normas de desarrollo.

(2) Respecto a la segunda, si la sola falta de desarrollo legislativo fuese razón para frustrar la aplicación directa de los derechos constitucionales, entonces estos derechos no constituirían el fundamento mismo del orden político, sino una concesión graciosa de éste. Que no haya una ley reglamentando el ejercicio de un derecho constitucional, y que se tome esa ausencia como argumento para fundar la inacción de los poderes públicos con respecto a tal derecho, significa invocar el hecho propio consistente en la inacción legislativa, para justificar una violación a la Constitución. Tal argumento cae por su propia base. Para tener asidero, la Constitución tendría que ser cosa distinta a una norma que garantice el ejercicio de los derechos a través de la institución de un gobierno de poderes limitados. Si uno de los 
órganos de gobierno no ha honrado sus competencias, los costos de su inacción no pueden transferirse al ciudadano. Y si el derecho cuya tutela se reivindica es uno que por su naturaleza necesita de mayor desarrollo que el brindado por la norma constitucional, el órgano autorizado para su aplicación será el encargado de dársela para el caso concreto. Se trata de lo que la teoría general del derecho conoce como una laguna técnica, causada por la indeterminación de la norma aplicable. Siempre que la norma es indeterminada, la autoridad llamada a aplicarla no rehúye su aplicación, sino que la aplica determinado su contenido. Se trata, por tanto, de uno de los supuestos que por definición dicen de la aplicación del derecho como función normativa: la integración de sus normas.

(3) Y, respecto a la tercera consecuencia, que un derecho deba interpretarse a favor de su ejercicio deriva del hecho que la Constitución existe precisamente para garantizar su ejercicio, en idéntica forma en que las competencias de los poderes públicos deban interpretarse restrictivamente es consecuencia de que la Constitución haya instaurado un gobierno de poderes limitados, haciendo de las habilitaciones normativas la técnica para la organización jurídica del poder. Interpretar a favor del ejercicio de un derecho significa preferir las construcciones que le den mayor eficacia. Esto es, no caer en formalismos (degeneración del pensamiento formal), desviando los requisitos formales de sus genuinos fines de seguridad, para convertirlos en obstáculos que, por la desproporción entre lo que protegen y lo que impiden, lesionen los derechos cuya tutela se reivindica. Aplicación inmediata de esto es, por ejemplo, el principio de trascendencia de las nulidades procesales, adoptado siempre por la jurisprudencia constitucional (STC 731/2010-AAC, 26 de julio, párrafo III.3), como también la flexibilización jurisprudencial del cumplimiento de los requisitos formales del recurso de casación (STC 2210/2012-AAC, 8 de noviembre, párrafo III.2).

\section{INTERPRETACIÓN SEGÚN LOS TRATADOS DE DERECHOS HUMANOS}

Los derechos se interpretan según los tratados de derechos humanos porque éstos forman parte del bloque de constitucionalidad. En lo atinente a estos tratados, el artículo 410.II supuso llevar al texto expreso de la Constitución la jurisprudencia ya existente del Tribunal Constitucional. Ya éste había tomado el artículo 35 del texto anterior de la Constitución como "permiso expreso" para la incorporación de normas al bloque de constitucionalidad. Interpretado como norma incorporante, el artículo 35 fue tornado en puerto de entrada de derechos y garantías que nacían de la soberanía del pueblo y de la forma republicana de gobierno, pero que no estaban literalmente enunciadas en el texto de la Constitución. La primera vez que se hizo mención al bloque de constitucionalidad fue en la STC 95/2001-RDI (21 de diciembre, párrafo V.2). En ella, aunque los límites del bloque ya estaban claros (i.e. los tratados sobre derechos humanos), no se argumentaba sobre su fuente positiva. El artículo 35 ni siquiera mereció mención. Ya para la STC 1662/2003-RAC (17 de noviembre, párrafo III.2) el artículo 35 fue tomado como norma incorporante, pero el Tribunal desarrolló mejor su justificación en la STC 45/2006-RDI (2 de junio, párrafo II.5.1). Aquí, sin embargo, comenzó usando un lenguaje cercano al concepto de constitución material. Afirmó que las normas del bloque eran tales por virtud a sus "cualidades intrínsecas". Pero las cualidades intrínsecas (materia) que debía tener una norma para integrar el bloque de constitucionalidad estaban decididas por la propia Constitución, a través de la norma interpretada como incorporante. Por tanto, el concepto de bloque de constitucionalidad se fundaba en el 
concepto formal de constitución. Por lo mismo, la declaratoria de inconstitucionalidad de una norma contraria al bloque debía sustanciarse como una violación del artículo 35 del texto formal de la Constitución.

Normativamente, que los tratados sobre derechos humanos fueran normas constitucionales llevaba consigo la incorporación de su significado jurídico tal como había sido definido por los órganos autorizados para su interpretación. Por esto, los precedentes de la Corte Interamericana de Derechos Humanos también eran parte del bloque de constitucionalidad. Era consecuencia de que la Convención Americana sobre Derechos Humanos otorgase competencia a la Corte para aplicar e interpretar la Convención (artículo 62) y para producir decisiones autoritativas al respecto (artículo 67). Por tanto, negar el carácter vinculante de los precedentes hubiese supuesto violar la propia Convención, en la medida que suponía desconocer la calidad de órgano autoritativo que tiene la Corte. Obedecer los precedentes era también una exigencia práctica, porque suponía que el Estado se comportase según las normas que serían usadas para su enjuiciamiento. Pero el Tribunal Constitucional no se pronunció sobre la incorporación de la jurisprudencia sino hasta el 2010, en la STC 110/2010-AAC (10 de mayo, párrafo III.3). A partir de acá, la incorporación de la jurisprudencia interamericana tuvo sustento expreso en el derecho positivo de fuente judicial. De ahí que, invocando dicha sentencia, el Tribunal haya recurrido a los asuntos "Baena Ricardo y otros vs. Panamá" (2001), "Tribunal Constitucional vs. Perú" (2001) y "Herrera Ulloa vs. Costa Rica” (2004), para explicar que las garantías insertas en el debido proceso son por igual aplicables en sede administrativa (STC 140/2012-AAC, 14 de mayo, párrafo III.1.1); y haya recurrido a este último también para justificar la inconstitucionalidad del delito de desacato (STC 1250/2012-AIC, 20 de septiembre, párrafo III.3.1); así como haya recurrido a los asuntos "De La Cruz Flores vs. Perú (2004) y "Vélez Loor vs. Panamá" (2010) para justificar la inaplicación de la retroactividad penal en materia de corrupción (artículo 123 de la Constitución), por contraria al favor rei (STC 770/2012-AIC, 13 de agosto, párrafo III.4.1).

Como los tratados de derechos humanos son normas de jerarquía constitucional, sus relaciones con las normas que integran el texto formal de la Constitución sólo pueden definirse por un criterio de relacionamiento intranormativo. Tal criterio es el de especialidad. Según este criterio, de presentarse una antinomia entre una norma del texto formal de la Constitución y una contenida en un tratado sobre derechos humanos, la resolución del conflicto consiste en demostrar que, en realidad, no hay antinomia. Para esto, debe interpretarse el supuesto de hecho de la norma del texto formal como siendo lo suficientemente general como para cobijar el supuesto especial de la norma de fuente internacional, eliminándose la antinomia con la aplicación preferente de esta última.

El mérito de la Constitución ha sido explicitar este razonamiento. (1) Ya siendo los tratados de derechos humanos parte de la Constitución desde 2001, y (2) siendo aquellos especiales en su materia respecto de ésta, pues (3) en caso de antinomia el intérprete tenía que decantarse por la norma de fuente internacional, excepto cuando (4) su especialidad supusiese un obstáculo para la efectividad de los derechos, en cuyo caso debía aplicar el texto formal de la Constitución, que fue instituido para garantizar su ejercicio.

(1) Repárese en el contenido del artículo 13.IV de la Constitución: "Los tratados y convenios internacionales ratificados por la Asamblea Legislativa Plurinacional, que reconocen los derechos humanos y que prohíben su limitación en los estados de excepción, prevalecen en el orden interno. (...)". El texto "y que prohíben su limitación en los estados de excepción" podría llevar a entender que sólo prevalecerán en el orden interno los tratados de derechos humanos que contengan tal prohibición. Pero esta no es una interpretación posible. 
Resulta antinómica con el artículo 410.II, que hace que cualquier tratado sobre derechos humanos tenga jerarquía constitucional. En consecuencia, el significado jurídico que dicho texto está predicando es la especialidad de las normas que menciona en relación con las demás normas constitucionales (tanto las del texto formal como las incorporadas). Como la unidad del sistema jurídico impide sostener que el artículo 13.IV esté diciendo lo que su tenor literal, en efecto, dice, debe rescatarse su sentido normativo apelando a su especialidad. Esto permite demostrar que no contradice lo dispuesto por el artículo 410.II. Así, (1) el artículo 410.II establece la supremacía constitucional llana de todos los tratados sobre derechos humanos, pero (2) eso no es antinómico con que durante el estado de excepción la aplicación de tales tratados se rija por la regla especial del artículo 13.IV reconstruido: prevalecen entre todas las normas constitucionales de la materia (supremacía constitucional llana), aquellas que prohíban la limitación de los derechos humanos durante el estado de excepción (aplicación del criterio de especialidad entre normas del mismo rango).

(2) Que el criterio de especialidad regula las relaciones entre las normas constitucionales sobre derechos humanos está claro en el texto expreso del artículo 256.I: los tratados sobre derechos humanos que "declaren derechos más favorables a los contenidos en la Constitución, se aplicarán de manera preferente sobre ésta". Al igual que en el caso del artículo 13.IV, aquí la preferencia no está en función de la jerarquía (porque todas las normas son del mismo rango), sino de la especialidad. Y tal cosa es la que se ha hecho con el artículo 123 de la Constitución en relación con la Declaración Universal de los Derechos Humanos (artículo 11.2), la Convención Americana sobre Derechos Humanos (artículo 9) y el Pacto Internacional de Derechos Civiles y Políticos (artículo 15.1). Compulsados todos ellos con los artículos 13.IV y 256 de la Constitución, el Tribunal razonó que la aplicación retroactiva de la ley penal no podía ir más allá del favor rei, inaplicando así él la letra expresa del texto formal de la Constitución, que permite la retroactividad penal "en materia de corrupción, para investigar, procesar y sancionar los delitos cometidos por servidores públicos contra los intereses del Estado" (artículo 123).

(3) Con forma de regla de interpretación, el artículo 256.II introduce al sistema una norma sobre la producción jurídica (fuente). Establece que los derechos reconocidos en la Constitución se interpretarán de acuerdo a los tratados internacionales sobre derechos humanos "cuando éstos prevean normas más favorables". Excepto la parte entrecomillada, el mismo texto está en el artículo 13.IV. Para ambos artículos debe entenderse que la regla de interpretación supone la especialidad de los tratados de derechos humanos respecto del texto formal de la Constitución, tomando como criterio específico de especialidad su carácter más favorable para los derechos humanos. Que la mención expresa al carácter más favorable no esté en el texto del artículo 13.IV no quiere decir que no sea parte de su significado jurídico. Las constituciones existen para instituir gobiernos de poderes limitados; la regla general para su interpretación es leerlas a favor de los derechos fundamentales.

(4) Entre los artículos 196.II y 256.II de la Constitución existe una relación de medios a fines. El primero dice que el Tribunal Constitucional aplicará, con preferencia, los criterios de interpretación gramatical e histórico, y el segundo dice que los derechos se interpretarán de acuerdo a los tratados, cuando éstos prevean normas más favorables. Este último, en consecuencia, establece un telos: favorecer el ejercicio de los derechos. Respecto de esto, el primero es un instrumento: es el medio que tiene el Tribunal Constitucional para decidir si es la norma de fuente internacional, o es si el texto formal de la Constitución, la norma que más favorece a un derecho. Los criterios de interpretación, en sí mismos, carecen de sustantividad propia. Son instrumentos al servicio de los fines del sistema jurídico. Por tanto, aplicar la 
norma que favorezca a los derechos es un fin que gobierna la interpretación constitucional, no un criterio instrumental, como al parecer lo ha entendido el Código Procesal Constitucional (artículo 2.II.2).

\section{RESERVA MATERIAL DE LEY}

Por su contenido, el artículo 109.II es una garantía institucional. Dice que los derechos "sólo podrán ser regulados por ley", lo que significa (1) que no pueden ser regulados por otra forma normativa y (2) que la ley no puede privarlos de su contenido. Esto venía ya de las reformas de 1861. Ya en ellas la Constitución impuso que los derechos y garantías "no [podrían] alterarse por las leyes que reglamenten su ejercicio" (artículo 18). Al igual que la fórmula actual, se trataba de una reserva material, pero que debía ser objeto de reconstrucción. Así, si correspondía al Poder Legislativo reglamentar el ejercicio de los derechos, entonces no correspondía a ningún otro; donde debía asumirse que al decir "ley", la Constitución estaba diciendo ley en sentido formal, por tratarse de la Constitución de una república. Esta misma fórmula se mantuvo hasta las reformas de 1938, cuando su texto pasó a ser una afirmación: "toda persona tiene los siguientes derechos fundamentales, conforme a las leyes que reglamenten su ejercicio" (artículo 6); manteniéndose la prohibición de alteración de los derechos como un artículo independiente (artículo 28). De 1938 a 2009 el cambio ha sido en el énfasis: de "conforme a las leyes" a "sólo" por ley. Pero de 1861 a 2009 la constante es la misma: queda sobrentendido que al decir "ley" se trata de una ley formal, por tratarse de una Constitución republicana, como, sin necesidad de mayor razonamiento, lo entendió el Tribunal Constitucional en 1999, en una escueta, pero hito, sentencia en la materia (STC 17/1999-RDI, 6 de diciembre, párrafo III.2). En este sentido, que la Constitución de 1826 no hubiese tenido una norma expresa al respecto, no quiere decir que los derechos no tuviesen que ser regulados sólo por ley. No hace falta decir que en una república el órgano con mayor legitimidad democrática es el legislativo y que, en un gobierno de poderes limitados instituido para garantizar el ejercicio de los derechos, por fuerza debe corresponder a dicho órgano su regulación. Y, lo mismo, está demás decir que la falta de una prohibición específica de alterar los derechos no los deja desguarnecidos, porque su carácter inviolable deviene del carácter normativo de la norma constitucional que los contiene.

Por la reserva formal la ley puede regular todo lo que la Constitución no ha atribuido a otros órganos. Esta concesión al Poder Legislativo es consecuencia de la mayor legitimidad democrática que ostenta. Que la ley lo pueda todo, dentro del límite dicho, pareciera hacer irrelevante el principio de reserva legal (reserva material de ley), que hace que una materia sólo pueda ser regulada por ley formal. Pero no es así. El principio de reserva legal fue originalmente formulado para las organizaciones jurídicas de legitimidad monárquica. Aquí la reserva significaba limitar la competencia normativa general del Poder Ejecutivo. Como el principio organizativo era monárquico, correspondían al rey todas las competencias que la constitución no le hubiese privado (una norma general excluyente a su favor). Su poder era un derecho propio de carácter originario (anterior a la constitución). Para asegurar que asuntos como, por ejemplo, la propiedad y la libertad fueran decididos en asamblea, había que "reservarlos" a su favor, excluyendo al rey de su tratamiento. En la organización jurídica de legitimidad democrática, en cambio, los poderes públicos sólo pueden actuar en virtud de habilitaciones normativas. Aquí el objeto del principio de reserva legal consiste en imponer al legislador el deber de regular por sí mismo una materia determinada. Esto limita su 
competencia para dejar a la potestad reglamentaria la regulación de la materia reservada. Potestas delegata non potest delegari (DC 6/2000-CCP, 21 de diciembre, párrafo III.2). Si lo hiciera, la delegación violaría la cláusula de reserva, en este caso, el artículo 109.II, causando la inconstitucionalidad del acto legislativo delegante como de la forma normativa delegada (vg. un decreto), como ocurrió con el Código Tributario (artículo 146), que remitía a la potestad reglamentaria la regulación de los plazos, términos, condiciones, requisitos y forma de los recursos de alzada y jerárquico (STC 9/2004-RDI, 28 de enero, párrafo III.5). Hasta aquí los efectos de la reserva material en relación a otras fuentes.

Si la reserva material ha sido instituida como garantía de los derechos, por definición, la ley no puede privarlos de su contenido. Una ley que, en nombre del artículo 109.II, legislase así, sería inconstitucional. Tomar este artículo como una competencia ilimitada es un exceso de formalismo. Olvida que la hipótesis de los derechos vacíos supone una negación de la propia Constitución, instituida para garantizar su ejercicio. Desde 2001 el Tribunal Constitucional ha adoptado la garantía del contenido esencial, excluyendo de regulación el núcleo esencial de los derechos, que no puede ser afectado para que no se "altere el derecho como tal" (STC 4/2001-RDI, 5 de enero, párrafo V.2). Interpretativamente, esta construcción cogía pie en el artículo 229 del anterior texto constitucional, que prohibía la alteración de los derechos por las leyes que regulasen su ejercicio. Al decir "el derecho como tal", el Tribunal estaba haciendo suya la teoría absoluta del contenido esencial, que sostiene que los derechos están definidos por una específica esfera permanente, que existe como una medida preestablecida fija determinable en forma abstracta. Hoy el contenido del anterior artículo 229 está en el artículo 13.I. Prohibir la alteración de los derechos (artículo 229) es jurídicamente lo mismo que prohibir su violación (artículo 13.I). Con esto, (1) el precedente constitucional que viene de 2001 sigue vigente, porque la norma constitucional que le da fundamento, como acto interpretativo, no ha cambiado, y (2) al no haber cambiado la norma constitucional, el Tribunal Constitucional puede mantenerse aferrado a la teoría absoluta o abordar la garantía del contenido esencial desde su vertiente relativa. Ambas opciones son constitucionalmente válidas, porque ambas son definiciones operativas del concepto jurídico de inviolabilidad, aunque la segunda parece ser más apropiada para pensar el derecho constitucional, para el que desde la tercera década del siglo XX las categorías absolutas comenzaban a serle ajenas y no así las cuestiones de grado.

\section{TUTELA EN SEDE CONSTITUCIONAL}

La Constitución dedica un capítulo a las “Acciones de Defensa”. Allí están las acciones de (1) libertad, (2) amparo (3) protección de privacidad, (4) inconstitucionalidad, (5) cumplimiento y (6) la acción popular. Pero las acciones (4) y (5) no son acciones de naturaleza tutelar.

De las que quedan como acciones de tutela, la acción de libertad y el amparo constitucional son las más antiguas. La primera viene de las reformas de 1938 (artículo 8) y, respecto de las reformas de 2009, la innovación ha consistido en ampliar el objeto procesal de su pretensión, sumando el derecho a la vida al derecho a la libertad (artículo 125), que era por definición el objeto de esta acción. Su desarrollo jurisprudencial más notable ha sido consolidarse como un medio de defensa contra particulares (STC 258/2012-AL, 29 de mayo, párrafo III.1), cuestión que, salvo alguna sentencia excepcional en dicho sentido (STC 1304/2002-RHC, 28 de octubre, párrafo III.2), no lograba tramontar la creencia, impuesta por 
su antigüedad pero no por su razonabilidad constitucional, en sentido que las privaciones a la libertad entre particulares eran fuero exclusivo del derecho penal.

La acción de amparo fue introducida en las reformas de 1967 (artículo 19). Su mayor desarrollo ha sido jurisprudencial, como también su mayor retroceso y reivindicación.

(1) Respecto a su desarrollo, el mismo causó tensiones entre el Tribunal Constitucional y la entonces Corte Suprema. Aquí se dijo que el Tribunal se inmiscuía en cuestiones privativas de la jurisdicción ordinaria y que generaba inseguridad jurídica. Ambas acusaciones se reducían a la revisión por vía de amparo de decisiones de la jurisdicción ordinaria. Desde su sentencia hito en la materia (AC 111/99-RAC, 6 de septiembre, último considerando), el Tribunal condicionó la revocación de las decisiones de la jurisdicción ordinaria a la violación de derechos fundamentales. Esto no ha variado (STC 1093/2012AAC, 5 de septiembre, párrafo III.2). En estos casos, el Tribunal no invade la competencia de la jurisdicción ordinaria, sino que se limita a ejercer la suya propia. La razón: todo acto de aplicación del derecho está sujeto a las garantías constitucionales para el ejercicio de la jurisdicción $\mathrm{y}$, por tanto, a la competencia del Tribunal Constitucional para su enjuiciamiento. Si no fuera así, habría que asumir que las decisiones de la jurisdicción ordinaria estarían fuera del sistema jurídico. Por tanto, si las decisiones de la jurisdicción ordinaria derivan su validez de la Constitución, entonces el análisis por vía de amparo del respeto a los derechos y garantías constitucionales no debe suscitar controversia alguna.

(2) Su mayor retroceso fue desconocer la naturaleza constitucional del derecho al juez preconstituido por ley (STC 99/2010-RAC, 10 de mayo, párrafos III.4 a III.7). El Tribunal Constitucional dijo que a esta garantía correspondía un "resguardo reforzado". Esto es correcto. Pero él mismo se desdijo: su interpretación importaba, al cabo, negar que esta sea una garantía de fuente constitucional, porque sólo no siéndola se justificaba que no la tutele, y como el Tribunal de hecho le había esquivado la prestación de tutela, había terminado diciendo, a pesar suyo, que no nacía de la Constitución. Pero luego esto mismo fue reconocido por el propio Tribunal al reencausar su jurisprudencia y reivindicar el derecho al juez preconstituido por ley como una garantía constitucional (STC 693/2012-AAC, 2 de agosto, párrafo III.2).

Desde su institución, el objeto de la pretensión de la acción de amparo abarcó siempre todos los derechos de índole constitucional. Pero en las reformas de 2004 se dotó a los derechos a la intimidad y a la privacidad de una acción propia, aunque por remisión expresa su procedimiento era el mismo que el de la acción de amparo (artículo 23.V). Ese fue el origen de la acción de privacidad, hoy inscrita en el artículo 130 y la remisión de su procedimiento al de la acción de amparo en el artículo 131.I. Careciendo de un procedimiento y de una instancia propia, las reformas de 2004 escindieron ociosamente el amparo. Que los derechos a la intimidad y a la privacidad no hubiesen estado expresamente mencionados en el texto de la Constitución hasta la incorporación de la acción de privacidad, no quiere decir que no fuesen derechos constitucionales. Ellos nacían del artículo 6.II, que hacía inviolables la dignidad y la libertad. Que en una república la intimidad y la privacidad sean parte de la esfera de libertad protegida es cosa que no necesita de mayor construcción, lo mismo que no necesita de mayor argumento que intimidad y privacidad hagan parte del concepto jurídico de dignidad. Antes de 2004, por tanto, podía también protegerse estos derechos, usando la acción de amparo.

La acción popular es una innovación de la Constitución de 2009. El objeto de su pretensión es la protección de los "derechos e intereses colectivos, relacionados con el patrimonio, el espacio, la seguridad y salubridad pública, el medio ambiente y otros de similar naturaleza" (artículo 135). A partir de acá, el Tribunal Constitucional ha interpretado 
que el objeto de su pretensión se extiende también (1) a los derechos e intereses difusos, (2) a otros derechos e intereses colectivos y difusos distintos a los enunciados en el texto formal, no obstante provengan de fuente legal, y (3) a otros derechos, por su vinculación con los derechos e intereses tutelados por la acción popular (STC 176/2012-AP, 14 de mayo, párrafo III.1). Aunque la Constitución también remite su tratamiento procesal al de la acción de amparo (artículo 136.II), la acción popular no es subsidiaria del agotamiento previo de los medios ordinarios de defensa (artículo 136.I). Son sujetos activos de la pretensión toda persona a título individual o en representación de una colectividad (la legitimación amplia es consecuencia del carácter colectivo del objeto procesal) y, obligatoriamente, el Ministerio Público y el Defensor del Pueblo en el ejercicio de sus funciones (artículo 136.II); mientras que son sujetos pasivos de la misma toda autoridad o todo particular que, por acción $\mathrm{u}$ omisión, viole o amenace violar los derechos o intereses objeto de tutela por esta vía. El carácter colectivo del objeto de la pretensión extiende sus efectos a la cosa juzgada. Habiéndose pronunciado una decisión de fondo, la cosa juzgada quedará constituida por la identidad de objeto, causa y colectividad, ya que la decisión, por pronunciarse sobre un derecho o interés colectivo, produce sus efectos sobre toda la colectividad, y no únicamente sobre el específico sujeto accionante.

La acción de cumplimiento no tutela derechos, con mucho que el Tribunal Constitucional arribe a la conclusión contraria, al casar la razón de su pretensión con la posible existencia de un daño "directo o indirecto" a un derecho (STC 258/2011-ACU, 16 de marzo, párrafo III.1.5). No es de naturaleza tutelar, porque el objeto de su pretensión es garantizar la ejecución de las disposiciones constitucionales o legales cuyo cumplimiento hubiese sido omitido (artículo 134). La Constitución es clara: no hace a la razón de su pretensión que el incumplimiento hubiese dañado o amenazare dañar un derecho constitucional. Sólo exige como fundamento el hecho del incumplimiento. A contrario, si hubiese violación de un derecho constitucional a causa de la omisión de un acto debido, la vía no sería la acción de cumplimiento, sino el amparo por omisión. Al haberse alejado del principio de unidad de acción y pluralidad de pretensiones, la Constitución ha optado por un sistema de acciones mutuamente excluyentes. Y como en su seno no pueden haber antinomias, ella misma ha hecho que los actos de incumplimiento dañinos para los derechos constituyan la razón de la pretensión del amparo por omisión (artículo 128), y ha excluido del fundamento de la acción de cumplimiento el daño constitucional a un derecho. En este sentido, no debe confundirse la exigencia de fundamentar la afectación que sufre el accionante (artículo 134.II), con la razón de la pretensión de la acción de cumplimiento. Lo primero es una condición de admisibilidad, que deriva del carácter concreto de la acción. No es una acción abstracta, no vinculada a un caso concreto, resoluble por el mero interés académico del actor. De ahí que quien la interponga deba fundamentar su interés para actuar, para echar a andar la jurisdicción. Lo segundo es una condición de la pretensión, de su éxito o de su fracaso, pero necesaria para decidirla sustantivamente.

No hay un derecho a hacer valer, en vía de acción de cumplimiento, la interpretación de una disposición normativa. La interpretación de una norma corresponde a su órgano de aplicación. Sólo si por irrazonable viola derechos constitucionales, puede la jurisdicción constitucional revisarla en vía de amparo (STC 452/2011-AAC, 18 de abril, párrafo III.2). Por exclusión, entonces, la acción de cumplimiento sólo puede ordenar la ejecución de disposiciones constitucionales claras y expresas. Y cuando se trata de disposiciones de fuente legal, sólo hacen a la acción de cumplimiento aquellas leyes a las que la Constitución se remita expresamente, delegándoles el desarrollo de un determinado contenido fijado por ella, 
tal como, por ejemplo, la ley que desarrolle la composición, la organización y el funcionamiento del Tribunal Constitucional (artículo 197.III). Esto, dicho en disenso con lo sostenido por el Tribunal Constitucional (STC 862/2012-ACU, 20 de agosto, párrafo III.1), para el que es demandable de cumplimiento por esta vía (1) no solo cualquier ley en sentido formal, sino (2) también cualquier norma general (i.e. ley en sentido material, por eso dice "ley sin importar la fuente de producción, abarcando, por tanto, a decretos supremos, resoluciones supremas, la legislación departamental y municipal"). Si por la acción de cumplimiento se pudiera demandar la ejecución de cualquier ley, la distinción entre jurisdicción constitucional y jurisdicción ordinaria se diluiría. Siendo aquella una acción constitucional, está para defender la Constitución, no la legalidad ordinaria. Por consiguiente, cuando la Constitución incluye en el objeto de su pretensión el incumplimiento de la ley (artículo 134.I), tal objeto debe leerse según el sistema de garantías al que pertenece, esto es, como medio de defensa de la propia Constitución. Y como es una acción instaurada para defender los mandatos claros y expresos de la Constitución, la demanda de cumplimiento de una ley no puede sino estar atada a dichos mandatos. Por tanto, al exigirse el cumplimiento de dicha ley, se está exigiendo el cumplimento, por devolución, de la disposición constitucional que ordenó tal remisión legislativa. Pero al extender sin más el objeto de la acción de cumplimiento a la tutela del principio de legalidad, el Tribunal Constitucional ha transmutado su naturaleza constitucional en la que debería ser una de las pretensiones de un proceso contencioso-administrativo de jurisdicción plena, que condene a la Administración a dar o a hacer a consecuencia de una demanda por la omisión de un acto debido.

Que la acción de inconstitucionalidad es de control normativo fluye de los artículos 132 y 133 de la Constitución. Ella está para defender su integridad objetiva. Su efecto jurídico es la invalidez del derecho ordinario (objeto) que viole directamente el clausulado constitucional (razón). Nace de la Constitución como acción directa y abstracta (artículo 202.1) y como incidente a un proceso principal. En esto consiste que toda persona afectada por una norma inconstitucional esté autorizada para promoverla (artículo 132), porque que alguien esté afectado por una norma quiere decir que será objeto de su aplicación. No hace, en consecuencia, a la razón de su pretensión la existencia de daño a un derecho constitucional.

El Tribunal ha reivindicado el incidente de inconstitucionalidad, al revertir las limitaciones a las que había sido objeto. Ya en la STC 3/2007-RII (17 de enero) lo hizo aplicable en el arbitraje, desdiciéndose del absurdo que suponía que, mientras que en la jurisdicción ordinaria debía juzgarse según el derecho constitucionalmente válido, en el arbitraje podía resolverse sin consideración sobre la constitucionalidad del derecho aplicable (AC 147/2005-CA, 8 de abril, párrafo II.2). Tal consecuencia sólo sería plausible si el arbitraje exorbitara el sistema constitucional. No siendo extrasistémico, es simplemente insostenible. Pero las limitaciones seguían. El incidente sólo estaba permitido de presentarse en procesos administrativos y judiciales y contra las normas a aplicarse en la decisión de fondo sobre la materia litigiosa (STC 67/2003-RII, 22 de julio, párrafo III.1). A contrario, el incidente estaba vedado de presentarse (1) en procedimientos administrativos (la distinción entre proceso y procedimiento se la hizo en la STC 9/2004-RDI, 28 de enero, párrafo III.4), (2) contra normas aplicables a incidentes (AC 25/2010-CA, 23 de marzo, párrafo II.3), (3) en la solicitud de tutela cautelar (AC 226/2010-CA, 17 de mayo, párrafo II.5), (4) contra cualquier norma procesal (AC 266/2010-CA, 26 de mayo, párrafo II.3), (5) contra normas que regulan el término de prueba (AC 360/2010-CA, 22 de junio, párrafo II.5), (6) en la formulación de excusas y recusaciones (AC 366/2010-CA, 22 de junio, párrafo II.5), (7) contra normas que regulan los actos de conocimiento (AC 392/2010-CA,30 de junio, párrafo II.5), y (8) en ejecución de sentencia (AC 450/2010-CA, 12 de julio, párrafo II.5). No fue 
hasta la STC 658/2012-AII (2 de agosto, párrafo III.3) cuando estas restricciones fueron superadas. Pero esta sentencia ha mantenido la prohibición de presentar el incidente de inconstitucionalidad en el curso de una acción de amparo (AC 257/2010-CA, 26 de mayo, párrafo II.3). Este límite es correcto, pero no porque la acción de amparo deba ser expedita, que es lo que argumenta el Tribunal. Para gozar de corrección racional, este argumento debiera aceptar, como fundamento implícito, que las violaciones a la Constitución no son reprochables siempre y cuando se las consolide con la debida prontitud. Es un hecho que el Tribunal no tolera este razonamiento, por eso que haya aclarado que, en las acciones de amparo, es a los propios jueces de garantías a quienes corresponde imponer la supremacía de la Constitución, aplicándola con preferencia al derecho ordinario que le fuera contrario. Para ahorrarse este rodeo, bastaba con reparar en la distinta naturaleza de la acción de amparo y del incidente de inconstitucionalidad. Mientras que la razón de la pretensión en la primera es el daño a un derecho constitucional, la razón de la pretensión en la segunda es un conflicto normativo. Por tanto, que no pueda presentarse el incidente de inconstitucionalidad en el curso de una acción de amparo es una consecuencia que viene de sus distintos objetos procesales.

La declaratoria de inconstitucionalidad tiene efectos pro-futuro. Así que las sentencias ya pasadas en autoridad de cosa juzgada, fundamentadas en la aplicación del derecho ordinario declarado luego inconstitucional, son irrevisables. Su estabilidad es consecuencia de la presunción de validez: ellas se justificaron en una norma que en su momento se estimaba válida y que, por tanto, producía sus efectos también válidamente. Pero esto no es aplicable a las sentencias en materia penal: aquí rige el favor rei, que es de fuente constitucional (artículo 123). Por tanto, al imputado le es aplicable retroactivamente la declaratoria de inconstitucionalidad que le es beneficiosa. A fortiori, la misma consecuencia es extensiva al derecho administrativo sancionador, porque, si se permite lo más, por fuerza debe permitirse lo menos (a maiore ad minus). Como la sentencia puede declarar la constitucionalidad o la inconstitucionalidad de la norma impugnada, si es lo segundo, dice la Constitución que la hace "inaplicable" con "efectos respecto a todos" (artículo 133). Lo mismo decía antes (artículo 121.II). En naturaleza jurídica se trata de una declaración de invalidez. Si la norma es válida, entonces existe como derecho $\mathrm{y}$, en consecuencia, es aplicable. Si la norma es inválida, no existe y, por consiguiente, es inaplicable. Desde este punto de vista, la redacción constitucional es redundante: una norma que no existe porque es inválida es una norma que no puede aplicarse a nadie. 


\section{Breve currículo:}

\section{Horacio Andaluz Vegacenteno}

Profesor de derecho, Master en Derecho Internacional (Universidad Complutense de Madrid), antiguo alumno de la Academia de La Haya de Derecho Internacional, Master of Laws-Derecho Constitucional y Filosofía del Derecho (Harvard Law School). Última publicación: Aplicación judicial de la constitución"(El País/Iuris Tantum/UPSA, Santa Cruz 2010, reimpresión 2011). Otros libros: Positivismo normativo y derecho internacional (Plural/CERID, La Paz 2005). Otras publicaciones (relevantes): "Cádiz en Charcas: Conjeturas e Indicios" (84 Revista de Derecho Político. UNEDMadrid 2012); "La posición constitucional del poder judicial" (80 Revista de Derecho Político. UNEDMadrid 2011). 